\title{
Saúde coletiva: uma "nova saúde pública" ou campo aberto a novos paradigmas?
}

Collective health: a "new public health" or field open to new paradigms?

Jairnilson S. Paim e Naomar de Almeida Filho

Instituto de Saúde Coletiva da Universidade Federal da Bahia. Salvador, BA - Brasil

PAIN, Jairnilson S. e Naomar de Almeida Filho, Saúde coletiva: uma "nova saúde pública" ou campo aberto a novos paradigmas? Rev. Saúde Pública, 32 (4): 299-316, 1998 


\title{
Saúde coletiva: uma "nova saúde pública" ou campo aberto a novos paradigmas?
}

\author{
Collective health: a "new public health" or field open \\ to new paradigms?
}

\author{
Jairnilson S. Paim e Naomar de Almeida Filho
}

Instituto de Saúde Coletiva da Universidade Federal da Bahia. Salvador, BA - Brasil

\begin{abstract}
Resumo
Trata-se de ensaio que apresenta um estudo exploratório da retórica paradigmática da saúde com o objetivo de analisar os principais elementos de discurso dos movimentos ideológicos que historicamente construíram o campo social da saúde, particularmente na segunda metade do século XX. São destacados os esforços empreendidos pela Organização Panamericana da Saúde para debater a teoria e a prática da saúde pública na região das Américas cotejando-os com as demandas emergentes no contexto econômico, político e social dos países latino-americanos. Neste particular, destaca-se a necessidade de construir uma agenda política comum, a partir da confluência de três temáticas - reforma setorial, "Renovação da Saúde para Todos" (RSPT) e "nova saúde pública", contemplando os planos doutrinário, conceitual, metodológico e operativo. Apresenta-se uma breve sistematização do marco conceitual da saúde coletiva, em elaboração na América Latina, situando mais particularmente as suas potencialidades de construção de um conhecimento transdisciplinar. Conclui-se que, apesar de em si não constituir um paradigma, a saúde coletiva, enquanto movimento ideológico comprometido com a transformação social, apresenta possibilidades de articulação com novos paradigmas científicos capazes de abordar o objeto saúde-doença-cuidado respeitando sua historicidade e integralidade.
\end{abstract}

Saúde pública, tendências. Medicina social.

Correspondência para/Correspondence to: Jairnilson S. Paim - Rua Padre Feijó, 29 - $4^{\circ}$ andar - Canela - $40210-270$ Salvador, BA - Brasil 


\begin{abstract}
The present essay is an exploratory study of the historical and institutional background of the so-called "crisis in public health", aimed at identifying the new trends and perspectives for the paradigmatic transformation of the health field in the context of the current international panorama of economic and cultural globalization. First, the rhetoric of health is analysed in historical perspective, briefly considering the main elements of the discourse of the ideological movements that historically built the social field of health. Medical Police, Social Medicine and Public Health are included as representative of such movements in $19^{\text {th }}$ century Westem Europe. After the Flexnerian turn, these movements were followed by Preventive Medicine, Community Health, Primary Health Care and Health Promotion, which dominated the scene particularly in the second half of the $20^{\text {th }}$ century. The authors also summarise recent concerted PAHO efforts to debate the theory and practice of Public Health in the Americas, vis à vis the emerging demands of the economic, political and social context of Latin American countries. In this regard, the need for a common political agenda is emphasized, with the convergence of three topics sectorial reform, "Renovation of Health for All" and the "new public health", covering the conceptual, methodological and operative domains. Secondly, a brief systematic account of the conceptual landmarks of the Collective Health movement, as carried through in the two last decades in Latin America, is presented, focusing more particularly on its potential for building up both a domain of transdisciplinary knowledge and a universe of practices. As a field of knowledge, it contributes to the study of health-disease phenomena in populations as a social process, investigating the production and distribution of disease in society as an aspect of social reproduction, and analysing health practices as a labor process integrated into the other social practices. As a universe of practices, Collective Health focuses on its models or action guidelines four objects of intervention: policies (forms of power distribution); practices (behavior modification; culture; institutions; knowledge production; institutional, professional and relational practices); technologies (organization and regulation of productive resources and processes; bodies/environments), and instruments (means of production of interventions). Finally, it is concluded that, although not being in itself a paradigm, Collective Health, as a movement committed to the social transformation of health, presents some possibilities of articulation with new scientific paradigms capable of approaching the healthdisease-care object with due regard to its historicity and complexity.
\end{abstract}

Public health, trends. Social medicine.

\section{INTRO D U ÇÃO}

Nesta segunda metade do século XX, a humanidade tem experimentado rápidas e profundas transformações em todas as esferas da vida econômica, cultural, social e política, talvez como nunca em sua história ${ }^{11,28,46}$. A internacionalização da produção, distribuição e consumo, juntamente com o avanço das tecnologias da informação, tem como resultado a globalização da economia e suas conseqüências macroeconômicas: transnacionalização empresarial, desterritorialização da força de trabalho, desemprego estrutural, entre outras. Ao mesmo tempo, verifica-se aumento das desigualdades entre os povos e os grupos sociais, a eclosão de movimentos nacionalistas, a exacerbação dos conflitos étnicos, a agressão ao meio ambiente, a deterioração do espaço urbano, a intensificação da violência e o desrespeito aos direitos humanos ${ }^{46}$.

No caso da saúde, o debate sobre as suas relações com o desenvolvimento econômico e social que marcou a década de sessenta amplia-se, nos anos setenta, para uma discussão sobre a extensão de cobertura dos serviços. O reconhecimento do direito à saúde e a responsabilidade da sociedade em garantir os cuidados básicos de saúde possibilitam o estabelecimento do célebre lema "Saúde para Todos 
no Ano 2000" (SPT-2000) ${ }^{85}$. Entretanto, enquanto a estratégia da atenção primária à saúde se difunde a partir da Conferência de Alma-Ata, os centros hegemônicos da economia mundial revalorizam o mercado como mecanismo privilegiado para a alocação de recursos e questionam a responsabilidade estatal na provisão de bens e serviços para o atendimento de necessidades sociais, inclusive saúde. A "nova ordem mundial" que se instaura na década de oitenta, inspirada no neoliberalismo, provoca uma marcante fragilização dos esforços para o enfrentamento coletivo dos problemas de saúde. Particularmente, nos países de economia capitalista dependente, a opção pelo "estado mínimo" e o corte nos gastos públicos como resposta à chamada "crise fiscal do estado" em muito comprometem o âmbito institucional conhecido como saúde pública.

Com base nesse quadro, constata-se uma "crise da saúde pública", percebida de modo diferente pelos distintos sujeitos atuantes neste campo social $^{28,33,39,46,60}$. Para a superação dessa crise, vários aportes têm sido propostos, cada um deles apontando para a necessidade de novos paradigmas no "campo da saúde pública"”.* Neste esforço, pode-se incluir desde as iniciativas da Organização Panamericana da Saúde (OPS) de reavaliar a "teoria e prática da saúde pública" ${ }^{\circ 5}$, até a proposição de uma Nova Saúde Pública como parte do movimento de renovação da estratégia "saúde para todos" ${ }^{33,86}$, e ainda a iniciativa do Banco Mundial de debater as "prioridades na pesquisa \& desenvolvimento em saúde" 87 .

Nesse contexto, faz-se necessário e urgente discutir a questão da saúde no âmbito públicocoletivo-social e as propostas de ação subseqüentes. No caso específico da América Latina, a emergência nos últimos vinte anos de um campo que se designou como Saúde Coletiva ${ }^{61}$ permite a identificação de pontos de encontro com os movimentos de renovação da saúde pública institucionalizada, seja como campo científico, seja como âmbito de práticas, e mesmo como atividade profissional. Nessa perspectiva, as propostas de consolidação do campo da saúde como forma de superação da chamada "crise da saúde pública" podem significar uma oportunidade para efetivamente incorporar o complexo "promoçãosaúde-doença-cuidado" em uma nova perspectiva paradigmática, aumentando assim a viabilidade das metas de Saúde Para Todos mediante políticas públicas saudáveis, através de maior e mais efetiva participação da sociedade nas questões da vida, saúde, sofrimento e morte.

Em pauta, encontra-se a necessidade de construção de um marco teórico-conceitual capaz de reconfigurar o campo social da saúde, atualizando-o face às evidências de esgotamento do paradigma científico que sustenta as suas práticas. No presente texto, buscou-se compreender esse marco conceitual enquanto corpo doutrinário estruturador de um dado campo científico (e seu paradigma dominante) e um âmbito de práticas. Trata-se de um estudo exploratório da retórica paradigmática do campo da saúde, consubstanciada nas redes produtoras e difusoras dos seus elementos ideológicos. Para realizá-lo, em primeiro lugar, analisa-se resumidamente os principais elementos de discurso dos movimentos ideológicos que historicamente construíram o campo social da saúde da II Guerra Mundial até a conjuntura atual, em que se almeja uma renovação das bases da saúde pública. Em seguida, apresenta-se uma tentativa de sistematização do marco conceitual da saúde coletiva, em construção na América Latina, situando mais particularmente as suas potencialidades de constituição de um conhecimento transdisciplinar. Em conclusão, pretende-se propor que este movimento ideológico pode melhor se articular a novos paradigmas científicos capazes de abordar o objeto complexo saúde-doença-cuidado respeitando sua historicidade e integralidade.

\section{MO VIMENTOS NO CAMPO SO CIAL DA SAÚ DE}

Terris (1992) ${ }^{81}$ atualiza a clássica definição de saúde pública elaborada por Winslow, na década de vinte, nos seguintes termos: "a arte e a ciência de prevenir a doença e a incapacidade, prolongar a vida e promover a saúde física e mental mediante os esforços organizados da comunidade". A partir dessa concepção, esse autor prescreve quatro tarefas básicas para a teoria e a prática de uma "Nova Saúde Pública": prevenção das doenças não infecciosas,

Observa-se cada vez mais uma ampliação do uso do termo paradigma para tratar de qualquer tipo de conhecimento humano e, de um modo ainda mais alargado, para referir-se a práticas sociais de qualquer natureza. Atualmente, pode-se encontrar desde uma equivalência do paradigma ao conceito amplo de campo disciplinar, como na noção de "paradigma da saúde pública", ${ }^{1}$ até um tratamento mais regionalizado de paradigma no sentido da mera atitude perante uma instituição como, por exemplo, nos múltiplos usos que o termo vem adquirindo no campo das ciências da gestão ${ }^{77}$. Em nível intermediário, no próprio campo da saúde, documentos oficiais de construção doutrinária têm feito uso do termo na conotação de modelo ou abordagem como, por exemplo, a noção de "paradigma da atenção primária à saúde" ${ }^{54}$. Como mencionado em outra oportunidade ${ }^{6}$, trata-se de utilização indevida de uma categoria cujo sentido técnico encontra-se razoavelmente estabelecido no campo teórico da filosofia da ciência, particularmente na abordagem de crítica histórica de Thomas Kuhn ${ }^{41}$. 
prevenção das doenças infecciosas, promoção da saúde, melhoria da atenção médica e da reabilitação.

Frenk $^{33}$ (1992) considera como campo de aplicação da "Nova Saúde Pública" as condições e respostas assentadas nas bases científicas das ciências biológicas, sociais e comportamentais, tendo como áreas de aplicação populações, problemas e programas. Para melhor delimitar o novo campo científico, esse autor desenvolve uma tipologia da investigação em saúde, distinguindo os níveis de atuação individual e subindividual, onde se concentram a pesquisa biomédica e a pesquisa clínica, em relação ao nível populacional que toma como objetos de análise as condições (pesquisa epidemiológica) e as respostas sociais frente aos problemas de saúde (pesquisa em sistemas de saúde - políticas de saúde, organização de sistemas de saúde, investigação em serviços e recursos de saúde).

Testa $^{83}$ (1992), ao analisar as respostas sociais no campo da saúde pública, denomina "atenção primitiva à saúde" aquela adotada nos países que dispõem de serviços diferenciados para distintos grupos sociais e que estão preocupados, fundamentalmente, em reduzir os gastos em saúde organizando serviços de segunda categoria para uma população considerada inferior. A partir de uma reflexão sobre as políticas sociais ${ }^{82}$, e buscando o redimensionamento teórico da saúde como "campo de força" e de aplicação da ciência, esse autor reconhece a saúde pública enquanto uma prática social, uma construção histórica, portanto.

A importante contribuição das abordagens etnográficas contemporâneas da prática científica, especialmente no contexto da chamada "virada hermenêutica"13, indica que os âmbitos da prática humana não se configuram a partir de uma estrutura racional de base normativa ou prescritiva, nem pela vertente doxológica (da doutrina), com o estabelecimento de objetivos hetero-regulados, nem pelo viés epistemológico formal. Em outras palavras, nem definições - mesmo aquelas exaustivas e objetivas como por exemplo a definição WinslowTerris, nem estruturas lógicas descritivas - como a classificação de Frenk são capazes de dar conta do essencial dos campos científicos e seus respectivos âmbitos de prática. Mas se as proposições das políticas de saúde e as prescrições da saúde pública são contextualizadas num "campo de força" como pode-se apreender a partir da crítica histórica de Testa, outros sentidos e significados podem ser extraídos dessa retórica. Por isso, antes de analisar os elementos discursivos das novas propostas, é necessário uma contextualização das práticas e dos discursos que, nos últimos cinqüenta anos, vêm constituindo o campo social da saúde bem como seus efeitos sobre a estruturação dos discursos oficiais nacionais e internacionais. Antes ainda, serão repassadas brevemente as raízes históricas dos elementos discursivos e pragmáticos dos movimentos ideológicos do campo social da saúde.

A área da saúde, inevitavelmente referida ao âmbito coletivo-público-social, tem passado historicamente por sucessivos movimentos de recomposição das práticas sanitárias decorrentes das distintas articulações entre sociedade e Estado que definem, em cada conjuntura, as respostas sociais às necessidades e aos problemas de saúde. As bases doutrinárias dos discursos sociais sobre a saúde emergem na segunda metade do século XVIII, na Europa Ocidental, em um processo histórico de disciplinamento dos corpos e constituição das intervenções sobre os sujeitos ${ }^{31,32}$. Por um lado, a higiene, enquanto conjunto de normatizações e preceitos a serem seguidos e aplicados em âmbito individual, produz um discurso sobre a boa saúde francamente circunscrito à esfera moral. Por outro lado, as propostas de uma política (ou polícia) médica estabelecem a responsabilidade do Estado como definidor de políticas, leis e regulamentos referentes à saúde no coletivo e como agente fiscalizador da sua aplicação social, desta forma remetendo os discursos e as práticas de saúde à instância jurídico-política ${ }^{70}$.

No século seguinte, os países europeus avançam um processo macrossocial da maior importância histórica: a Revolução Industrial, que produz um tremendo impacto sobre as condições de vida e de saúde das suas populações. Com a organização da classes trabalhadoras e o aumento da sua participação política, principalmente nos países que atingiram um maior desenvolvimento das relações produtivas, como Inglaterra, França e Alemanha, rapidamente incorporam-se temas relativos à saúde na pauta das reivindicações dos movimentos sociais do período. Entre 1830 e 1880, surgem, nesses países, propostas de compreensão da crise sanitária como fundamentalmente um processo político e social que, em seu conjunto, receberam a denominação de Medicina Social ${ }^{70,78}$. Em síntese, postula-se nesse movimento que a medicina é política aplicada no campo da saúde individual e que a política nada mais é que a aplicação da medicina no âmbito social, curando-se os males da sociedade. A participação política é a principal estratégia de transformação da realidade de saúde, na expectativa de que das revoluções populares deveria resultar democracia, justiça e igualdade, principais determinantes da saúde 
social. Apesar de desbaratado no plano político, o movimento da medicina social gera importante produção doutrinária e conceitual que fornece as bases para os esforços subseqüentes de pensar a questão da saúde na sociedade $7,22,24,35,58,70,78$.

Em paralelo, principalmente na Inglaterra e nos Estados Unidos, estrutura-se uma resposta a esta problemática estreitamente integrada à ação do Estado no âmbito da saúde, constituindo um movimento conhecido como Sanitarismo ${ }^{78}$. Em sua maioria funcionários das recém-implantadas agências oficiais de saúde e bem-estar, os sanitaristas produzem um discurso e uma prática sobre as questões da saúde fundamentalmente baseados em aplicação de tecnologia e em princípios de organização racional para a expansão de atividades profiláticas (saneamento, imunização e controle de vetores) destinadas principalmente aos pobres e setores excluídos da população ${ }^{24,35,78}$. O advento do paradigma microbiano nas ciências básicas da saúde representa um grande reforço ao movimento sanitarista que, em um processo de hegemonização, e já então batizado de saúde pública, praticamente redefine as diretrizes da teoria e prática no campo da saúde social no mundo ocidental ${ }^{22}$.

No início deste século, com o célebre Relatório Flexner, desencadeia-se nos Estados Unidos uma profunda reavaliação das bases científicas da medicina, que resulta na redefinição do ensino e da prática médica a partir de princípios tecnológicos rigorosos. Com sua ênfase no conhecimento experimental de base subindividual, provenientes da pesquisa básica realizada geralmente sobre doenças infecciosas, o modelo conceitual flexneriano reforça a separação entre individual e coletivo, privado e público, biológico e social, curativo e preventivo ${ }^{68}$. É nesse contexto que surgem as primeiras escolas de saúde pública contando com pesados investimentos de organismos como a Fundação Rockefeller, inicialmente nos Estados Unidos e em seguida em vários países, inclusive na América Latina ${ }^{27}$. De fato, as referências paradigmáticas do movimento da saúde pública não expressam qualquer contradição perante as bases positivistas da medicina flexneriana, conforme demonstrado pelo processo de seleção das demandas de subvenção destinadas à institucionalização dos centros de formação de sanitaristas e epidemiologistas da época ${ }^{27,68}$.

Na década de quarenta, como uma conseqüência de processos externos e internos ao campo da saúde (por um lado, os reflexos sociais da crise econômica de 29, e por outro lado, o incremento de custos devido ao aumento da especialização e da tecnologização da prática médica) articula-se nos Estados Unidos propostas de implantação de um sistema nacional de saúde ${ }^{7}$. Pela ação direta do poderoso lobby das corporações médicas daquele país, no lugar de uma reforma setorial da saúde nos moldes da maioria dos países europeus, propõe-se mudanças no ensino médico nele incorporando uma vaga ênfase na prevenção. Em 1952, realiza-se em Colorado Springs uma reunião de representantes das principais escolas de medicina norte-americanas (incluindo Canadá), ponto de partida para uma ampla reforma dos currículos de cursos médicos no sentido de inculcar uma atitude preventiva nos futuros praticantes ${ }^{7,22}$.

No nível da estrutura organizacional, propõe-se a abertura de departamentos de medicina preventiva substituindo as tradicionais cátedras de higiene, capazes de atuar como elementos de difusão dos conteúdos de epidemiologia, administração de saúde e ciências da conduta até então abrigados nas escolas de saúde pública ${ }^{45,78}$. Nesta proposta, o conceito de saúde é representado por metáforas gradualistas do processo saúde-enfermidade, que justificam conceitualmente intervenções prévias à ocorrência concreta de sinais e sintomas em uma fase préclínica $^{45}$. A própria noção de prevenção é radicalmente redefinida, através de uma ousada manobra semântica (ampliação de sentido pela adjetivação da prevenção como primária, secundária e terciária) que termina incorporando a totalidade da prática médica ao novo campo discursivo. Que isto tenha ocorrido somente no nível da retórica indica apenas a limitada pretensão transformadora do movimento em pauta, efetivamente preso no que Arouca $^{7}$ com muita perspicácia denominou de "dilema preventivista".

Com entusiasmo compreensível, organismos internacionais do campo da saúde aderem de imediato à nova doutrina, orquestrando uma internacionalização da Medicina Preventiva já franca-mente como movimento ideológico ${ }^{7}$. Na Europa, realizamse congressos no modelo Colorado Springs em Nancy (França), no mesmo ano de 1952, e em Gotemburgo (Suécia) no ano seguinte, patrocinados pela Organização Mundial da Saúde (OMS); na América Latina, sob o patrocínio da OPS, são organizadas os Seminários de Viña del Mar (Chile) em 1955 e de Tehuacán (México) em 1956 7,22,37.

O sucesso deste movimento no seu país de origem é inegável: a única nação industrializada que até hoje não dispõe de um sistema universal de assistência à saúde é justamente os Estados Unidos. Na América Latina, apesar das expectativas e investimentos de organismos e fundações internacionais, o único efeito 
deste movimento parece ser a implantação de departamentos acadêmicos de medicina preventiva em países que, já na década de sessenta, passavam por processos de reforma universitária ${ }^{7,78}$. Na Europa ocidental, em países que já dispunham de estruturas acadêmicas de longa tradição e que no pós-guerra consolidavam sistemas nacionais de saúde de acesso universal e hierarquizados, a proposta da medicina preventiva não causa maior impacto nem sobre o ensino nem sobre a organização da assistência à saúde ${ }^{37}$.

Os célebres anos sessenta marcam nos Estados Unidos uma conjuntura de intensa mobilização popular e intelectual em torno de importantes questões sociais, como os direitos humanos, a guerra do Vietnã, a pobreza urbana e o racismo. Diversos modelos de intervenção são testados e institucionalizados sob a forma de movimentos organizados no âmbito local das comunidades urbanas, destinados principalmente à ampliação da ação social nos setores de habitação, educação e saúde (particularmente saúde mental), reduzindo tensões sociais nos guetos das principais metrópoles norte-americanas ${ }^{24}$. No campo da saúde, organizase então o movimento da saúde comunitária, também conhecido como medicina comunitária*, baseado na implantação de centros comunitários de saúde, em geral administrados por organizações não lucrativas porém subsidiados pelo governo federal, destinados a efetuar ações preventivas e prestar cuidados básicos de saúde à população residente em áreas geograficamente delimitadas 1,22,24,42. $^{7}$.

A proposta da saúde comunitária inegavelmente recupera parte importante do arsenal discursivo da medicina preventiva, particularmente a ênfase nas então denominadas "ciências da conduta" (sociologia, antropologia e psicologia) aplicadas a problemas de saúde. Nesse caso, entretanto, o conhecimento dos processos socioculturais e psicossociais destina-se não a facilitar a relação médico-paciente ou a gestão institucional em saúde, como no movimento precedente, mas sim a possibilitar a integração das equipes de saúde nas comunidades "problemáticas", através da identificação e cooptação dos agentes e forças sociais locais para os programas de educação em saúde ${ }^{24}$. Em um certo sentido, o movimento da saúde comunitária consegue colocar em prática alguns dos princípios preventivistas ${ }^{58}$, evidentemente focalizando setores sociais minoritários e deixando mais uma vez intocado o mandato social da assistência médica convencional.

Desta feita, o fracasso do movimento da saúde comunitária, artificial e distanciado do sistema de saúde predominante no país de origem, parece evidente ${ }^{24,42,58}$. Neste particular, Desrosiers ${ }^{22}$ chega a ser irônico, ao comentar que nos Estados Unidos, dado "o caráter parcial e muitas vezes temporário das experiências de medicina ou saúde comunitária, restou somente a expressão (...) no lugar da saúde pública tradicional". Não obstante, mais uma vez, organismos internacionais do campo da saúde rapidamente incorporam o novo movimento ideológico, traduzindo o seu corpo doutrinário às necessidades dos diferentes contextos de aplicação potencial ${ }^{7,22,24}$. Com o endosso da OMS, os princípios desses programas comunitários de saúde passam a enfatizar mais a dimensão da assistência simplificada visando à extensão de cobertura de serviços para populações até então excluídas do cuidado à saúde, principalmente em áreas rurais, sendo dessa maneira incorporados ao discurso das agências oficiais (secretarias, ministérios) de saúde. Efetivamente, data de 1953 a definição dos "serviços básicos de saúde" da $\mathrm{OMS}^{86}$, cobrindo as seguintes atividades: a) atenção à saúde da mulher e da criança; b) controle de doenças transmissíveis; c) saneamento ambiental; d) manutenção de sistemas de informação; e) educação em saúde; e) enfermagem de saúde pública; f) assistência médica de baixo grau de complexidade. A revisão de 1963, desta definição, realizada por uma comissão de especialistas já engajados no movimento da saúde comunitária, propõe incluir nesta relação a participação ${ }^{54}$.

$\mathrm{Na}$ América Latina, programas de saúde comunitária são implantados principalmente na Colômbia, no Brasil e no Chile, sob o patrocínio de fundações norte-americanas e endossados pela OPS, na expectativa de que o seu efeito-demonstração poderia influenciar positivamente o desenho dos sistemas de saúde no continente ${ }^{24}$. Em um plano mais geral, há mais de 20 anos (1977), a Assembléia Mundial da Saúde lança a consigna Saúde para Todos no Ano 2000, assumindo uma proposta política de extensão da cobertura dos serviços básicos de saúde com base em sistemas simplificados de assistência à saúde ${ }^{60,86}$. No ano seguinte (1978), em Alma Ata, a Conferência Internacional sobre Atenção Primária à Saúde, promovida pela OMS, reafirma a saúde como direito do homem, sob a responsabilidade política dos governos, e reconhece a sua determinação inter-

* Esta denominação é empregada na Europa e Canadá para designar departamentos de medicina preventiva e social, sem qualquer conotação de ação assistencial em comunidades ${ }^{37}$. 
setorial ${ }^{85,86}$. Além disso, estabelece a Atenção Primária à Saúde como estratégia privilegiada de operacionalização das metas da SPT-2000, implicitamente incorporando elementos do discurso da saúde comunitária. Mais tarde, já na década de oitenta, com o rótulo atualizado de SILOS (Sistemas Locais de Saúde) e dentro de um modelo distritalizado com base em níveis hierarquizados de atenção, a retórica da saúde comunitária integra-se às primeiras iniciativas de reforma setorial da saúde nos países subdesenvolvidos ${ }^{61}$.

Em 1974, no Canadá, o documento conhecido como Relatório Lalonde ${ }^{16}$ define as bases de um movimento pela promoção da saúde, trazendo como consigna básica adicionar não só anos à vida mas vida aos anos. Estabelece o modelo do "campo da saúde" composto por quatro pólos: a biologia humana que inclui a maturidade e envelhecimento, sistemas internos complexos e herança genética; o sistema de organização dos serviços, contemplando os componentes de recuperação, curativo e preventivo; o ambiente, que envolve o social, o psicológico e o físico; e, finalmente, o estilo de vida, no qual podem ser considerados a participação no emprego e riscos ocupacionais, os padrões de consumo e os riscos das atividades de lazer. Propõe como estratégias considerar a gravidade dos problemas de saúde, a prioridade dos tomadores de decisão, a disponibilidade de soluções efetivas com resultados mensuráveis, os custos e as "iniciativas federais" centradas na promoção da saúde, na regulação, na pesquisa, na eficiência da atenção à saúde e no estabelecimento de objetivos.

Com base nesses princípios e estratégias, e no contexto do que veio a se chamar de revolution tranquile, implanta-se em várias províncias do Canadá uma rede de centros comunitários de saúde e serviços sociais, efetivamente integrados a um sistema de medicina socializada, que representa uma síntese dos modelos de atenção precedentes. De acordo com Desrosiers ${ }^{22}$, a reforma do sistema de saúde canadense teve como objetivos:

reunir os serviços sociais e os serviços de saúde sob a autoridade de um mesmo ministério chamado de Ministério dos Assuntos Sociais, nos mesmos estabelecimentos em âmbito local, os CLSC [Centros Locais de Serviços Comunitários], com uma equipe pluridisciplinar composta de agentes sanitários e sociais; favorecer uma medicina global pela prática nos CLSC e através de laços estreitos entre clínicos e especialistas da saúde pública no âmbito dos hospitais; enfim, assegurar uma participação importante dos cidadãos na administração dos serviços de saúde.

A Carta de Ottawa ${ }^{17}$, documento oficial que institucionaliza o modelo canadense, define os principais elementos discursivos do movimento da promoção da saúde: a) integração da saúde como parte de políticas públicas "saudáveis"; b) atuação da comunidade na gestão do sistema de saúde; c) reorientação dos sistemas de saúde; d) ênfase na mudança dos estilos de vida. Cronologicamente, este movimento corresponde ao desmantelamento do National Health Service da Inglaterra, na conjuntura do "tatcherismo", e à reforma dos sistemas de saúde e seguridade social dos países escandinavos, face ao recuo da socialdemocracia no continente europeu, o que restringe o seu potencial de expansão mesmo entre os países desenvolvidos. Nos Estados Unidos, na década de oitenta, desenvolvem-se programas acadêmicos levemente inspirados por esse movimento, sob a sigla HPDP (Health Promotion Disease Prevention), claramente indicando a opção pela proposta mínima de mudança de estilo de vida por meio de programas de modificação de comportamentos considerados de risco (como hábito de fumar, dieta, sedentarismo, entre outros). No que se refere à absorção do discurso da promoção da saúde pelos organismos internacionais, deve-se referir ao Projeto Cidades Saudáveis da OMS, lançado com bastante publicidade em $1986^{85}$. Vale ainda mencionar que o Banco Mundial, em conjunto com a Organização Mundial da Saúde, patrocina em 1991 atualização dos princípios do movimento da promoção da saúde, nele incorporando a questão do desenvolvimento econômico e social sustentado como importante pauta extra-setorial para o campo da saúde ${ }^{11,87}$. Além disso, no contexto da Conferência Mundial pelo Meio Ambiente, conhecida como ECO 92, promovida pela Organização das Nações Unidas no Rio de Janeiro, a saúde ambiental foi definida como prioridade social para a promoção da saúde, dentro da célebre Agenda $21^{85,86}$.

A essa altura, a receita neoliberal é adotada pelos organismos financeiros internacionais e imposta aos países que pretendem inserir-se na "nova ordem" do capitalismo mundial, sobretudo depois da derrocada do leste europeu e dos impasses do "socialismo real". Justamente nesse contexto a OPS promove, a partir de 1990, um debate sobre a crise da saúde pública privilegiando uma reflexão sobre os conceitos, teorias, metodologias, elementos explicativos, determinantes estruturais, repercussões operacionais e nas práticas de saúde, e perspectivas futuras para a saúde pública nas suas relações com o Estado e a socieda$\mathrm{de}^{28,46,55-57,65}$. Paralelamente, a OMS patrocina uma 
reflexão articulada sobre as bases de uma "Nova Saúde Pública", organizando um conjunto de seminários e reuniões sobre formação avançada, liderança institucional, teoria e prática em saúde pública ${ }^{33,54,85}$.

\section{A “NO VA SAÚ DE PÚ BLICA"}

Presentemente, diversos países realizam reformas econômicas, políticas e administrativas buscando assegurar algum espaço na nova configuração dos mercados mundiais. A reforma do Estado, ainda que não suficientemente explicitada, coloca-se na agenda política de governos com diferentes espectros político-ideológicos e, nesse particular, emergem propostas setoriais como é o caso da saúde. $\mathrm{Na}$ América Latina, muitas das reformas do setor saúde são apoiadas por organismos financeiros internacionais, a exemplo do Banco Mundial ${ }^{11}$, cujos pressupostos e diretrizes divergem bastante dos projetos originais de reforma sanitária. Portanto, fazse necessário discernir os conteúdos substantivos de cada um dos projetos para que, por exemplo, seja possível compreender as especificidades do sistema de saúde canadense em comparação com o projeto Clinton para a atualização do complexo de serviços de saúde estadunidense, do mesmo modo que se faz necessário considerar as diferenças entre a organização dos serviços de saúde em Cuba, com ênfase na atenção primária, e as propostas de reforma setorial da Bolívia e da Colômbia.

Respostas pragmáticas a tal "momento de verdade" 28 podem ser visualizadas, no caso da América Latina, através das propostas do Banco Mundial que valorizam a eficiência e a eficácia em detrimento da eqüidade mediante políticas de ajuste macroeconômico e, no setor saúde, através da focalização e da cesta básica de serviços ${ }^{11,87}$. Assim, muitas dessas reformas setoriais não chegam a ser concebidas nem debatidas pelas escolas de saúde pública ou organismos assemelhados e, em certos casos, passam ao largo dos próprios ministérios da saúde, sendo negociadas diretamente entre as agências financeiras e a "área econômica" dos governos.

Nesse contexto, uma reflexão sobre a "Nova Saúde Pública" que procura examinar, de modo crítico e profundo, os determinantes da "crise da saúde pública", passa a ser identificada pejorativamente como "assunto de sanitaristas", isto é, de escolas e pesquisadores do campo da saúde bem como de funcionários públicos com responsabilidades operativas. A correlação de forças políticas e institucionais vigente mantém afastados do cenário das reformas de vários países não só os trabalhadores do setor como especialmente os distintos segmentos da população que serão "objeto" dessas reformas. As conquistas democráticas alcançadas pelos povos latino-americanos e caribenhos, especialmente a partir da década de oitenta, ainda não foram suficientes para garantir a publicização (isto é: controle público das políticas e práticas institucionais dos respectivos Estados) dos seus aparelhos e mesmo das suas burocracias.

A linha mais pragmática, prescritiva e intervencionista adotada por um painel convocado pela OMS para discutir a "Nova Saúde Pública" (Genebra, 1995) ${ }^{86}$, em consonância com as visões de representantes europeus e americanos da saúde pública, não parece dar conta dos impasses identificados na região das Américas, particularmente na América Latina e Caribe. Como integram sistemas relativamente estabilizados em que as regras de jogo mudam lentamente, para eles a crise não é estrutural e representaria apenas uma dada interpretação de sanitaristas. Propõem assim a agregação de novos temas e habilidades ao campo da saúde pública ou ao seu âmbito de práticas e de instituições ${ }^{54,86}$. Todavia, este enfoque pode resultar em reformas curriculares das respectivas escolas ou em reformas administrativas nas instituições de saúde mas, seguramente, é insuficiente para dar conta de uma política de eqüidade, solidariedade e saúde tal como propõe a própria OMS neste final de século ${ }^{85}$.

Conseqüentemente, as instituições acadêmicas e de serviços do campo da saúde não podem ignorar o movimento que se engendra em torno da formulação de uma política global de saúde como componente diretivo do corpo doutrinário elaborado em função de uma proposta de "Renovação da Saúde para Todos" (RSPT) ${ }^{85}$. Desse modo, poderão reatualizar suas concepções e práticas acerca da saúde pública e, simultaneamente, estarão em condições de explorar oportunidades de diálogo e de construção de alianças entre organizações não governamentais e organismos de governo para o enfrentamento dos problemas de saúde. Entretanto, mais que diálogos e alianças, as instituições acadêmicas e de serviços podem produzir novos conceitos, teorias e práticas que, num processo de "interfertilização" so serão capazes de influir na própria doutrina da RSPT e na política de saúde a ser concebida quando se celebra 20 anos de AlmaAta.

Diante das dificuldades óbvias de se dispor de uma concepção convergente sobre a "Nova Saúde Pública", faz-se pertinente sistematizar algumas questões preliminares. Como os atores sociais que atenderam à convocação para este importante debate 
vêem o campo social da saúde e o perfil do profissional que atuará nos distintos âmbitos de ação? Que conteúdos devem ser privilegiados? Se o campo de conhecimento da saúde pública é tão amplo que não comporta um tipo único de profissional para atuar nas instituições e serviços, qual o núcleo básico de conhecimentos e habilidades que deverão compor o novo perfil profissional num contexto que incorpora novos atores para o seu âmbito de ação, exigindo capacidade de negociação, agir comunicativo e administração de conhecimentos?

Iniciativas recentes da $\mathrm{OPS}^{55}$ visando à liderança e à formação avançadas em saúde pública possibilitaram uma discussão ampliada dessa questão na Região das Américas, incluindo, portanto, o Canadá, os EUA e os países do Caribe. Assim, no período 1987-1988 procedeu-se à análise da infraestrutura privilegiando as seguintes áreas críticas: políticas públicas, sistemas de informação e desenvolvimento da epidemiologia, economia e financiamento, recursos humanos em saúde, desenvolvimento tecnológico e sistemas de serviços de saúde. Nos anos 1989-1990 foram realizados seminários para a análise da prestação de serviços no que diz respeito a recuperação da saúde, prevenção de doenças e promoção da saúde ${ }^{65}$. Finalmente, no período 1991-1995, a OPS encaminhou um ambicioso projeto para reflexão e crítica sobre a teoria e a prática da saúde pública ${ }^{55}$, tendo como referência os textos básicos e a reunião do "Grupo de Consulta" ocorrida em New Orleans, em 1991, culminando com a Primeira Conferência Panamericana de Educação em Saúde Pública ${ }^{8}$, realizada no Rio de Janeiro em 1994.

Esta breve resenha sugere um clima estimulante de efervescência teórica e crítica, propiciando pautas de ação apto para iniciar um processo de modernização conceitual apto para sustentar uma nova prática da saúde pública. Segundo Rodriguez ${ }^{69}$, para esta nova prática, necessita-se de novos profissionais, capazes de cumprir distintos papéis, desde uma função histórico-política de "resgatar, do próprio processo histórico de construção social da saúde, os conhecimentos, êxitos e fracassos da humanidade em sua luta pela cidadania e bem-estar" até uma função agregadora de valor através da produção e gestão do conhecimento científicotecnológico; desde uma função de gerência estratégica de recursos escassos e mediador estratégico das relações entre as necessidades e problemas de saúde e as decisões políticas até uma função de advocacy, utilizando o conhecimento "como instrumento de denúncia promovendo a mobilização crescente da sociedade em demanda de realização do seu potencial de saúde e exercício do direito de cidadania" $"$.

Nessa perspectiva, as escolas de saúde pública devem fortalecer o seu processo de independización. A I Conferência Panamericana sobre Educação em saúde pública (Rio de Janeiro, 1994) ${ }^{8}$ propôs o aprofundamento do debate em torno da transformação da estrutura organizacional das respectivas escolas, considerando a pertinência da desvinculação administrativa em relação às faculdades de medicina. De fato, o conceito de "espaço transdisciplinar" tende a desestruturar a idéia de faculdade ou escola como organização autosuficiente. Daí a proposta de criação de espaços de excelência que, à semelhança das novas organizações empresariais, funcionem como "redes institucionais agregadoras de valor" 8,69. A idéia básica é que se desenvolvam processos de formação e capacitação sistemáticos, criativos e inovadores, cujos eixos fundamentais serão a investigação e a articulação com os serviços de saúde. A produção de lideranças setoriais e institucionais passa a constituir um dos propósitos básicos das novas instituições acadêmicas:

Liderança setorial em saúde significa a capacidade do setor de transformar a saúde no referente básico para a formulação de todas as outras políticas públicas. A política de saúde condicionaria, em grande parte, não só comportamentos individuais, mas também ações coletivas, sociais e políticas. A liderança institucional é definida como a capacidade que possui uma organização de irradiar valores, gerar conhecimento e promover compromisso com esses valores, por parte da população e de outras organizações. Uma organização líder produz diferenças fundamentais na comunidade (...). Capacitar-se para a liderança é, portanto, um produto de aquisição de novos valores e habilidades, como o desenvolvimento de novos significados da missão e da filosofia institucionais. Como o objetivo da liderança é promover compromissos públicos com ideais básicos, o setor ou a instituição líder se reconhece não só pela qualidade de suas ações, mas principalmente pelo compromisso que gera nos setores, instituições ou atores que lidera" $\left(\mathrm{OPS}^{56}\right)$.

Podemos destacar, no caso do desenvolvimento da saúde pública na década de noventa, o seu caráter de movimento ideológico, seja utilizando o seu braço acadêmico (Associação Latino-Americana de Escolas de Saúde Pública-ALAESP, por exemplo) seja acionando o seu braço político-ideológico (OPS). Assim, a reflexão sobre as possibilidades de 
incorporação de novos paradigmas inscreve-se, embora não integralmente, no capítulo das políticas de saúde. As inflexões produzidas no campo do saber encontam-se subordinadas às modificações no âmbito das práticas, ainda que inovações conceituais e desenvolvimentos disciplinares, científicos e tecnológicos possam afetar a formulação e a implementação de algumas dessas políticas. Não se trata de uma determinação mecânica das políticas sobre o campo mas, em última análise, uma decisiva influência, já que é possível conceber situações em que produtos desse campo do saber exercem alterações, ainda que parciais, sobre a organização das práticas de saúde.

As modificações do panorama político e social do mundo e da situação de saúde (principalmente a falta de mudanças esperadas) põem em cheque as premissas e previsões dos antigos modelos. Ou talvez o problema seja mais profundo, no nível não dos modelos e sim do paradigma científico que fundamenta este campo de prática social e técnica ${ }^{2,5,69}$. Frente aos elementos discursivos e extra-discursivos ligados à constatação de um esgotamento dos paradigmas vigentes, desafiados pela "crise da saúde pública", surgem demandas por "novos paradigmas" $28,46,54$. No particular dos elementos discursivos, cabe destacar os pressupostos de que o desenvolvimento da saúde supõe a exclusão da doença e que a ciência e a técnica dispõem de um potencial inesgotável para superar a enfermidade. Como elementos extra-discursivos desse debate encontram-se as restrições econômicas que comprometem a capacidade do Estado suportar, a longo prazo, o custo crescente da atenção à saúde, particularmente a assistência médico-hospitalar, além do fato de que esta assistência não garante melhor nível de bem-estar ou produtividade social. Reconhece-se, ainda, a crescente iniqüidade dos "determinantes da saúde" 85 , seja no nível singular, relativo à qualidade do ambiente social, seja no nível geral, referente às disparidades da distribuição de renda e poder entre os segmentos sociais.

Entretanto, romper com os paradigmas vigentes não significa recusa pura e simples. Impõe movimentos de crítica, elaboração e superação. Tratase de uma construção no plano epistemológico ao tempo em que se mobilizam vontades no âmbito da práxis para alimentar o pensamento e a ação. Esperase que, ao se debater a reforma do setor saúde no contexto da RSPT, seja implementada uma práxis voltada para os "determinantes de saúde" a partir da qual se poderia construir um novo paradigma da saúde. A confluência das três temáticas - reforma setorial, RSPTe "nova saúde pública", impõe-se pela necessidade de uma agenda política comum, contemplando tanto os planos doutrinário e conceitual quanto o plano metodológico operativo.

Nessa perspectiva, faz-se necessário rever paradigmas e propostas de ação, visando a estabelecer balizamentos sobre a questão da saúde no âmbito coletivo. No caso específico da América Latina, a construção nos últimos vinte anos do movimento denominado saúde coletiva tem permitido um diálogo crítico e a identificação de contradições e acordos com a saúde pública institucionalizada, seja na esfera técnico-científico, seja no terreno das práticas. Em outras palavras, trata-se de considerar, no âmbito do interesse específico, as seguintes questões: Será que o movimento da saúde coletiva pode se apresentar como um novo paradigma científico, em um sentido rigorosamente delimitado? Que pautas epistemológicas, teóricas, metodológicas e políticas devem ser ativadas para alcançar mudanças paradigmáticas no campo da saúde? Pragmaticamente, que modelos de compreensão da situação de saúde poderão ser produzidos? Mais ainda, que efeitos terão tais transformações sobre a retórica e a prática no campo da saúde?

No restante do presente ensaio, será apresentada uma tentativa de sistematização do marco conceitual da saúde coletiva, em construção na América Latina, situando mais particularmente as suas potencialidades de constituição de um conhecimento transdisciplinar. Como conclusão, pretende-se propor que este movimento ideológico pode melhor se articular a novos paradigmas científicos capazes de abordar o objeto complexo saúde-doença-cuidado respeitando sua historicidade e integralidade.

\section{SAÚ DE CO LETIVA: CAMPO CIENTÍFICO E ÂMBITO DE PRÁTICAS}

Como ponto de partida, pode-se entender a saúde coletiva como campo científico ${ }^{14,67}$, onde se produzem saberes e conhecimentos acerca do objeto 'saúde' e onde operam distintas disciplinas que o contemplam sob vários ângulos; e como âmbito de práticas ${ }^{61}$, onde se realizam ações em diferentes organizações e instituições por diversos agentes (especializados ou não) dentro e fora do espaço convencionalmente reconhecido como "setor saúde". Assumir a saúde coletiva como um campo científico implica considerar alguns problemas para a reflexão. Trata-se, efetivamente, de um campo novo ou de um 
novo paradigma dentro do campo da saúde pública? Quais os saberes que dão suporte ao campo e, conseqüentemente, às práticas dos seus atores sociais? Quais os "obstáculos epistemológicos" que dificultam o seu desenvolvimento científico? Quais os “obstáculos da práxis" face à reorganização dos processos produtivos, à sociedade da informação, à reforma do Estado e das suas novas relações com a sociedade?

Algumas respostas provisórias a estas questões serão apresentadas nesta seção, ainda que um aprofundamento sobre a temática exija um texto de maior fôlego.

Originalmente, o marco conceitual* proposto para orientar o ensino, a pesquisa e a extensão em saúde coletiva no caso brasileiro, foi composto pelos seguintes pressupostos básicos $\left(\right.$ Paim $\left.^{59}\right)$ :

a) “A Saúde, enquanto estado vital, setor de produção e campo do saber, está articulada à estrutura da sociedade através das suas instâncias econômica e político-ideológica, possuindo, portanto, uma historicidade."

b) “As ações de saúde (promoção, proteção, recuperação, reabilitação) constituem uma prática social e trazem consigo as influências do relacionamento dos grupos sociais."

c) "O objeto da Saúde Coletiva é construído nos limites do biológico e do social e compreende a investigação dos determinantes da produção social das doenças e da organização dos serviços de saúde, e o estudo da historicidade do saber e das práticas sobre os mesmos. Nesse sentido, o caráter interdisciplinar desse objeto sugere uma integração no plano do conhecimento e não no plano da estratégia, de reunir profissionais com múltiplas formações" (...).

f) "O conhecimento não se dá pelo contato com a realidade, mas pela compreensão das suas leis e pelo comprometimento com as forças capazes de transformá-la".

Não obstante a adesão que tais pressupostos possam, ainda hoje, estimular, cabe ressaltar que o desenvolvimento da saúde coletiva, enquanto área do saber e campo de práticas, nos últimos anos permite recontextualizar alguns desses pressupostos. Assim, a definição do "objeto" acima apresentada sugere o entendimento da saúde coletiva como ciência ou disciplina científica. Em um momento posterior de discussão desse campo na América Latina, Fleury ${ }^{29}$ chega a definir saúde coletiva como "área de produção de conhecimentos que tem como objeto as práticas e os saberes em saúde, referidos ao coletivo enquanto campo estruturado de relações sociais onde a doença adquire significação".

Entretanto, o trabalho teórico-epistemológico empreendido mais recentemente aponta a saúde coletiva como um campo interdisciplinar e não propriamente como uma disciplina científica, muito menos uma ciência ou especialidade médica ${ }^{4,61,67}$. Cumpre ressaltar as influências mútuas entre esse desenvolvimento e os movimentos pela democratização das formações sociais latinoamericanas, especialmente os processos de reforma sanitária desencadeados em alguns países da região. De fato, o marco conceitual da saúde coletiva, tal como vem sendo construído a partir da década de 70 , resulta, de um lado, da crítica aos diferentes movimentos e projetos de reforma em saúde ocorridos nos países capitalistas e, de outro, da elaboração teórico-epistemológica e da produção científica, articuladas às práticas sociais.

A constituição da saúde coletiva, tendo em conta os seus fecundos diálogos com a saúde pública e com a medicina social, tal como vem se concretizando nas duas últimas décadas, permite uma delimitação compreensivelmente provisória desse campo científico, enquanto campo de conhecimento e âmbito de práticas. Enquanto campo de conhecimento, a saúde coletiva contribui com o estudo do fenômeno saúde/doença em populações enquanto processo social; investiga a produção e distribuição das doenças na sociedade como processos de produção e reprodução social; analisa as práticas de saúde (processo de trabalho) na sua articulação com as demais práticas sociais; procura compreender, enfim, as formas com que a sociedade identifica suas necessidades e problemas de saúde, busca sua explicação e se organiza para enfrentá-los.

$\mathrm{Na}$ América Latina, e no Brasil em particular, realiza-se nas duas últimas décadas um trabalho de construção de novas teorias, enfoques e métodos da epidemiologia e da planificação em saúde, além de investigações concretas buscando a aplicação de métodos das ciências sociais no campo da saúde coletiva $^{18,29,34,53,61}$. Desse esforço de reconstrução teórica, tem emergido no campo novos objetos de conhecimento e de intervenção, como por exemplo os casos da comunicação social em saúde e da vigilância em saúde. Nesse aspecto, cabe referir o desenvolvimento científico e tecnológico do campo mediante importantes contribuições nas áreas de

* Entende-se marco conceitual como Juan César Garcia, no sentido da "apresentação de um fenômeno ou acontecimento atendendo só as suas linhas ou características mais significativas, de modo a facilitar um certo nível de generalidade que o torna aplicável a situações distintas dentro de uma área semelhante" ${ }^{34}$. 
Epidemiologia Social ${ }^{12,15,19,43,44,66,79}$, Políticas e Práticas de Saúde 19,24-26,29,30,36,40,49-51,59-64,73-76, Planificação em Saúde ${ }^{47,48,73-76,80,82-84}$, e Epistemologia e Metodologia em Saúde 2-6,20-21,52,53,71-72.

Nessa perspectiva, a saúde coletiva pode ser considerada como um campo de conhecimento de natureza interdisciplinar cujas disciplinas básicas são a epidemiologia, o planejamento/administração de saúde e as ciências sociais em saúde. Este contempla o desenvolvimento de atividades de investigação sobre o estado sanitário da população, a natureza das políticas de saúde, a relação entre os processos de trabalho e doenças e agravos, bem como as intervenções de grupos e classes sociais sobre a questão sanitária ${ }^{67}$. São disciplinas complementares desse campo a estatística, a demografia, a geografia, a clínica, a genética, as ciências biomédicas básicas, entre outras. Esta área do saber fundamenta um âmbito de práticas transdisciplinar, multiprofissional, interinstitucional e transetorial.

Enquanto âmbito de práticas, a saúde coletiva envolve determinadas práticas que tomam como objeto as necessidades sociais de saúde, como instrumentos de trabalho distintos saberes, disciplinas, tecnologias materiais e não materiais, e como atividades intervenções centradas nos grupos sociais e no ambiente, independentemente do tipo de profissional e do modelo de institucionalização. Abrange, portanto, um

conjunto articulado de práticas técnicas, científicas, culturais, ideológicas, políticas e econômicas, desenvolvidas no âmbito acadêmico, nas instituições de saúde, nas organizações da sociedade civil e nos institutos de pesquisa, informadas por distintas correntes de pensamento resultantes da adesão ou crítica aos diversos projetos de reforma em saúde ${ }^{61}$.

Contudo, mais do que definiçõos formais, a saúde coletiva requer uma compreensão dos desafios que se colocam no presente e no futuro que transcendem o campo institucional e o tipo de profissional convencionalmente reconhecidos como da saúde pública. A possibilidade de redimensionar objeto, instrumentos de trabalho e atividades, considerando sua articulação com a totalidade social reabre alternativas metodológicas e técnicas para pensar e atuar no campo da saúde coletiva no trânsito para o novo milênio. Conforme destacado em uma das mais fecundas contribuições a esse debate,

os avanços da epidemiologia crítica, a epistemologia política, os novos aportes das ciências sociais, a planificação estratégica, a comunicação social e a educação popular têm constituído bases fundamentais para a elaboração de novos instrumentos de docência, investigação e cooperação com as organizações e instituições da sociedade civil do Estado. A própria experiência de resistência e luta em saúde por parte de nosso povo nos tem permitido encontrar em nossa história e cultura os elementos fundamentais para o avanço de nosso pensamento e ação(...). Não somente se necessitam conhecimentos para apreender a realidade, mas também se deve realizar uma aproximação gnoseológica distinta com vistas a encontrar na realidade - ademais de conhecimentos - saberes, desejos, sentidos, projeções de luta e mudança, que constituem também aspectos fundamentais da ação humana ${ }^{26}$.

A superação do biologismo dominante, da naturalização da vida social, da sua submissão à clínica e da sua dependência ao modelo médico hegemônico - cuja expressão institucional no âmbito das universidades é a sua subordinação funcional, política e administrativa às faculdades de medicina representam elementos significativos para o marco conceitual da saúde coletiva. Faz-se necessária, portanto, a identificação de uma "nova positividade" na articulação das dimensões objetiva e subjetiva no campo social da saúde. A retomada da problemática do sujeito não significa a negação das estruturas, do mesmo modo que a definição de um marco conceitual para a saúde coletiva não implica a adoção de um quadro teórico de referência exclusivo e excludente. Isto porque, segundo Granda ${ }^{36}$,

tanto o mundo natural, quanto o mundo social se encontram determinados e em constante devir, porém sua diferença radica em que no segundo o conhecimento se transforma em consciência e sentido de necessidade e necessidade de ação que encobre uma potencialidade para a ação; então, é necessário pensar que para poder estudar o processo saúdel enfermidade se requer considerar os sujeitos sãos $e$ enfermos não unicamente para explicá-los sim para compreendê-los e conjuntamente construir potencialidades de ação.

Conseqüentemente, a análise das relações entre as ciências sociais, a vida cotidiana e as ciências naturais, ao tempo em que examina a constituição dos sujeitos sociais, pode localizar essa "nova positividade", tanto na militância sociopolítica, quanto na incorporação tecnológica ${ }^{18,29,40}$. A valorização da dimensão subjetiva das práticas de saúde, das vivências dos usuários e trabalhadores do setor tem proporcionado espaços de comunicação e diálogo com outros saberes e práticas abrindo novas perspectivas de reflexão e de ação. A revisão crítica 
de algumas proposições tais como "campo de saúde" 23 , promoção da saúde (Carta de Ottawa, $1984)^{17}$, vigilância em saúde ${ }^{48}$, confere novos sentidos para as reflexões sobre a saúde coletiva no continente. Donnangelo $^{25}$ ilustra as potencialidades de tais redefinições:

A variedade e o caráter freqüentemente restrito e restritivo das conceptualizações do coletivo/social não invalidam o fato de que as práticas sanitárias se viram constantemente invadidas pela necessidade de construção do social como objeto de análise e como campo de intervenção. Nem devem induzir à suposição de que a vida social concreta acabe por tornar-se mero produto dessas opções conceituais. Ela irromperá, certamente, sob outras formas, também no campo do saber, quando as malhas conceituais e sociais se revelarem estreitas face à concretude dos processos sociais.

A discussão entre as finalidades das práticas de saúde e o seu objeto, meios de trabalho e atividades, bem como a análise das relações técnicas e sociais do trabalho em saúde como via de aproximação entre os modelos assistenciais e de gestão, constituem desafios teóricos e práticos para a saúde coletiva. Isto resulta de uma ampliação dos objetos de intervenção, a partir da noção de prevenção e atenção primária para os conceitos de qualidade de vida e promoção da saúde, como observam Schraiber e MendesGonçalves $^{74}$ no seguinte trecho:

A atenção primária vem progressivamente se tornando um complexo assistencial que envolve difíceis definições de tecnologia apropriada. Não só a medicina desenvolveu-se muito em seus diagnósticos precoces e definições de riscos genético-familiares, como epidemiologicamente a definição de situação de risco também se complexificou. Além dissso, a dimensão de ações que promovem diretamente a saúde, mais que ações de restauração ou prevenção, tornaram a promoção à saúde um conceito a ser melhor delimitado. Esta noção, mal esboçada nos anos 50, embora já presente enquanto intenção, traz novas questões para a assistência, como por exemplo uma melhor definição do conceito de qualidade de vida.

O fenômeno saúde tem sido também concebido como expressão do modo de vida (estilo e condições de vida $)^{66}$, capaz de explicar, juntamente com as condições de trabalho e do meio ambiente, o perfil epidemiológico da população. $\mathrm{O}$ estudo da situação de saúde, segundo condições de vida, tem privilegiado as articulações com quatro dimensões da reprodução social: a reprodução biológica onde se manifesta a capacidade imunológica e a herança genética; a reprodução das relações ecológicas, que envolve a interação dos indivíduos e grupos com o ambiente residencial e do trabalho; a reprodução das formas de consciência e comportamento, que expressam a cultura; e a reprodução das relações econômicas, onde se realizam a produção, distribuição e o consumo ${ }^{19,72}$. A partir desse modelo podem ser identificados diferentes espaços e estratégias de intervenção sanitária: a) indivíduos (espaço singular) - estratégias de alto risco; b) grupos sociais (espaço particular) - estratégias populacionais; c) modelos econômicos (espaço geral) - políticas de saúde ${ }^{19}$.

No que diz respeito às respostas sociais ao fenômeno saúde/doença a vigilância à saúde constitui uma "prática sanitária que organiza os processos de trabalho em saúde, sob a forma de operações, para confrontar problemas de enfrentamento contínuo, num território determinado" ${ }^{47}$. O modelo da vigilância em saúde contempla o processo saúde/ doença na coletividade e fundamenta-se na epidemiologia e nas ciências sociais, ao contrário do modelo da história natural das doenças que privilegia o indivíduo e a fisiopatologi $\mathrm{a}^{45}$. Ao considerar esquemáticamente danos, indícios de danos e de exposição, riscos e exposição propriamente dita e, last but not least, as necessidades e determinantes socioambientais, a vigilância em saúde permite orientar intervenções visando ao "controle de danos", "controle de riscos" e "controle de causas" (determinantes socioambientais) ${ }^{62}$. Abre, portanto, conforme Souza e Kalichman ${ }^{79}$, espaço para uma reatualização da reflexão e da ação no que se refere à promoção da saúde e à qualidade de vida:

Considerando, para tanto, os problemas já colocados relativamente à distribuição eqüânime no conjunto social das conquistas que beneficiam a vida coletiva, não resta dúvida de que tal indagação inicia-se obrigatoriamente pelo exame do que significará a qualidade de vida no plano coletivo, sem que isto anule as necessidades variadas que se colocam no plano individual (...). Transformando, a partir dessas mudanças, o modelo de organização tecnológica do trabalho em saúde, a prática da vigilância ousará, através dele, a inscrição de um outro 'modo de andar a vida' em sociedade.

A adoção de novos paradigmas no campo da saúde coletiva no âmbito das práticas enfrenta-se, portanto, com distintos desafios, na medida em que, de acordo com Paim ${ }^{61}$, as ações de saúde de alcance coletivo expressam uma tensão entre Estado $e$ Sociedade, entre liberdades individuais $e$ responsabilidades coletivas, entre interesses privados 
e públicos. A extensão e profundidade dessas ações depende da dinâmica de cada sociedade, sobretudo diante das articulações que estabelece concretamente com as instâncias econômicas, políticas $e$ ideológicas.

Portanto, a saúde coletiva privilegia nos seus modelos ou pautas de ação quatro objetos de intervenção: políticas (formas de distribuição do poder); práticas (mudanças de comportamentos; cultura; instituições; produção de conhecimentos; práticas institucionais, profissionais e relacionais); técnicas (organização e regulação dos recursos e processos produtivos; corpos/ambientes); e instrumentos (meios de produção da intervenção). Desse modo, mais do que qualquer outro movimento ideoló-gico, absorve a produção de conhecimentos inter/transdisciplinares com grande capacidade de "interfertilização" ${ }^{60}$, seja para a realização das suas funções essenciais, seja para o exercício das suas funções possíveis e desejáveis. Finalmente, enquanto âmbito de práticas, a saúde coletiva contempla tanto a ação do Estado quanto o compromisso da sociedade para a produção de ambientes e populações saudáveis, através de atividades profissionais gerais e especializadas.

Pode-se admitir que a crise da saúde como parte da crise social gera contradições diversas. Os atuais desafios da saúde coletiva não se limitam à formação profissional, à produção de conhecimentos, à renovação conceitual e epistemológica dentro do campo institucional presentemente ainda reconhecido como saúde pública. Tais desafios atravessam toda a organização social, desde a produção, distribuição e consumo de bens e serviços até as formas de organização do Estado e dos seus aparelhos nas suas relações com a sociedade e a cultura ${ }^{61,82}$.

Enfim, a saúde coletiva, entendida como "conjunto de saberes que dá suporte às práticas de distintas categorias e atores sociais face às questões de saúde/doença e da organização da assistência"25, encontra seus limites e possibilidades nas inflexões da distribuição do poder no setor saúde e numa dada formação social. Sublinhar o caráter histórico e estrutural da saúde coletiva significa reconhecer, teórica e empiricamente, um conjunto de práticas (econômicas, políticas, ideológicas, técnicas, e outras) que tomam como objeto as necessidades sociais de saúde. Representa um enfoque de práticas que não se submetem, acriticamente, ao modelo de saúde pública institucionalizado nos países centrais, seja enquanto tipo profissional ou modelo de organização de serviços de saúde. A saúde coletiva preocupa-se com a saúde pública enquanto saúde do público, sejam indivíduos, grupos étnicos, gerações, castas, classes sociais, populações. Nada que se refira à saúde do público, por conseguinte, será estranho à saúde coletiva ${ }^{61}$.

\section{CON CLU SÃO : CAMPO ABERTO A NOVOS PARADIGMAS}

Pode-se concluir que, apesar de não preencher as condições epistemológicas e pragmáticas para se apresentar, em si mesma, como um novo paradigma científico, a saúde coletiva se consolida como campo científico e âmbito de práticas aberto à incorporação de propostas inovadoras, muito mais do que qualquer outro movimento equivalente na esfera da saúde pública mundial. A partir destas reflexões, constatase a afirmação de um campo interdisciplinar dinâmico, renovado e recomposto a partir de uma produção teórica ousada e consistente, ainda enfrentando diversas interrogações e dilemas. De fato, a conjunção das "crises da saúde" - científica, econômica, social e política - lança complexos desafios para a saúde coletiva quanto ao que fazer para efetivamente se articular aos novos paradigmas da saúde para o século XXI.

No âmbito da produção de conhecimento, o passo mais importante será certamente re-configurar o objeto privilegiado 'saúde'. Isto deverá resultar de uma apreensão pragmática do objeto, não no sensocomum do imediatismo, e sim no sentido de que este deve alimentar uma práxis em vez de constituir-se em mera produção e incorporação de tecnologia. Muito do que em um dado paradigma se pode tomar como um aparente paradoxo deve-se ao fato de que não se lida com um objeto obediente às determinações da predição, aquela das antecipações limitadas e limitantes, rigorosas e precisas. Efetivamente, o objeto da saúde coletiva é muito mais tolerante a formas aproximadas de antecipação do seu processo, ressaltando a natureza não-linear da sua determinação e a imprecisão (ou borrosidade) dos seus limites. Então, será plenamente legítimo buscar a superação da prática preventiva preditiva desta saúde pública que tanto se conhece, tanto no sentido de sua aplicação ao indivíduo quanto em sua aplicação em geral, em direção a uma saúde coletiva previsional ou, pré-visionária, quer dizer, uma saúde coletiva capaz de propor visões, formas, figuras e cenários, em vez de predizer algumas poucas medidas e seus pobres efeitos.

Em nível teórico, muitos autores já assinalam a importância estratégica da re-construção do objeto da saúde coletiva. Acrescenta-se que este faz parte de uma nova família de objetos científicos, construído 
enquanto objeto totalizado e complexo. Para clarificar esta idéia, em outra oportunidade ${ }^{4}$, propôs-se uma analogia proveniente de um campo científico onde a predição é por definição relativizada, a meteorologia, onde ninguém acredita em predições mas muito se fala em previsões. O que é que define um furacão? Não é a medida da pressão barométrica, não é a velocidade dos ventos, não é a variação de temperatura, não é nada disso (que se pode estimar com um alto grau de precisão) mas é tudo isso, unificado em uma totalidade integral que se reconhece como o furacão, porém que não se reduz às suas medidas.

Por analogia, portanto, pode-se dizer que o objeto possível da promoção-saúde-enfermidade-cuidado, tal como um furacão, é um objeto de alta complexidade e que só se define em sua configuração mais ampla, já que tem facetas, ângulos distintos e a mirada de cada um destes ângulos não nos dá acesso à integralidade deste objeto. Pode-se chamá-lo de integrais de saúde-enfermidade-cuidado ${ }^{4}$. Os integrais de saúde-enfermidade-cuidado podem ser referenciados tanto como tecidos de pontos sensíveis ou metáforas de representação social de enfermidades, quanto como estruturas epidemiológicas, cadeias de causalidade ou relações de produção de risco. Em ambos os casos, trata-se de objeto por definição complexo e contextualizado, típico do neo-sistemismo das novas aberturas paradigmáticas assinaladas. A lógica que deve predominar em tais objetos possíveis é uma lógica múltipla e plural que não se pode expressar de uma maneira codificada, mas que somente se pode reconhecer por seus efeitos.

No âmbito dos processos de reprodução (ensino/ formação) da saúde coletiva enquanto campo de conhecimento com facilidade reconhece-se o potencial da fractalidade como princípio organizador do seu âmbito de práticas. Por um lado, em uma perspectiva dialética, a prática da saúde coletiva será "minimalista" e localizada e ao mesmo tempo holística e globalizante. Por outro lado, em uma perspectiva pragmática, a saúde coletiva enquanto âmbito de práticas se constituirá em um permanente processo de autocriação, balizada primordialmente pelos seus efeitos concretos sobre a realidade de saúde. Nesse sentido, os processos de produçãoreprodução deste campo poderão cumprir a seguinte pauta de ação:

a) qualificar o conjunto de necessidades sociais em saúde, entendendo-as não apenas como carências mas como "ideais de saúde" ou, alternativamente, como "projetos de vir a ser"; isto significa tomar a saúde como "meta a ser conquistada, como um bem que se adquire através dos conflitos e da luta de classe $^{52}$;"

b) pensar os diferentes meios e as atividades necessárias (o trabalho propriamente dito) para atender tais necessidades, ainda que não se restrinjam ao conhecimento científico e tecnológico da saúde coletiva e da medicina ${ }^{61}$;

c) instaurar novas relações técnicas e sociais orgânicas a tais práticas no campo social da saúde, a exemplo dos processos de distritalização e municipalização, educação e comunicação social, grupos de pressão, organizações não governamentais, produtores culturais, entre outros ${ }^{64}$,

d) investir política e tecnicamente nos espaços institucionais abertos por tais propostas, na medida em que, enquanto as necessidades de saúde são socialmente determinadas, as práticas de saúde coletiva são redefinidas tendo em conta o desenvolvimento dos seus instrumentos de trabalho e a instauração de novas relações internas ao campo da saúde ${ }^{61}$.

Isto implica desenvolver programas de educação permanente ou continuada em saúde coletiva ${ }^{63}$ nas instituições que prestam serviços de saúde, com vistas a recompor e atualizar constantemente os elementos das práticas de saúde - os objetos, os meios de trabalho, as atividades realizadas nessas práticas, e também para que, a partir dessa experiência democrática, sejam instauradas novas relações técnicas e sociais no processo de trabalho em saúde. Para além da produção de novos objetos de conhecimento e de práticas, trata-se ainda da criação de espaços institucionais e de momentos pedagógicos para a constituição de novos sujeitos sociais no interior dos próprios serviços de saúde.

Nos níveis político e sociocultural de constituição do campo da saúde coletiva, será conveniente explorar formas de organização dos sujeitos sociais não redutíveis a partidos e sindicatos (embora sem descartá-los), capazes de dar ânimo (vida) aos sonhos e esperanças de criar civilizações (ou socializações) pautadas no afeto, na solidariedade, na liberdade e na justiça. Conciliar este "mundo subjetivo" com o "mundo social" através de uma ação política emancipatória ${ }^{38}$ pode ser um dos maiores desafios para a práxis da saúde coletiva nos tempos atuais. A participação organizada dos grupos sociais, bem como o reconhecimento e o estímulo às iniciativas comunitárias, radicadas na solidariedade, constituem possibilidades de redefinição de relações sociais que poderão auxiliar na redução do sofrimento humano, na elevação da consciência sanitária e ecológica, na preservação da saúde e na defesa da vida. 


\section{REFERÊNCIAS}

1. AFIFI, A. \& BRESLOW, L. The mature paradigm of public health. Ann. Rev. Public Health, 15:223-35, 1994.

2. ALMEIDA FILHO, N. Epidemiologia sem números. Rio de Janeiro, Campus, 1989.

3. ALMEIDA FILHO, N. A clínica e a epidemiologia. Rio de Janeiro, APCE-ABRASCO, 1992.

4. ALMEIDA FILHO, N. New concepts and methodologies in public health research.Washington, D.C., Pan American Health Organization, 1996.

5. ALMEIDA FILHO, N. Transdisciplinaridade e saúde coletiva. Ciênc. Saúde Coletiva, 2(1/2):5-20, 1997.

6. ALMEIDA FILHO, N. \& PAIM, J.S. Usos e abusos da categoria 'paradigma' no campo da Saúde Coletiva. In: Congresso Brasileiro de Saúde Coletiva, 5., Águas de Lindóia, 1997. Resumos. Águas de Lindóia, ABRASCO, 1997.

7. AROUCA, A. S. O dilema preventivista: contribuição para a compreensão e crítica da medicina preventiva. Campinas, 1975. [Tese de Doutoramento - Universidade Estadual de Campinas].

8. ASOCIACIÓN LATINOAMERICANA Y DEL CARIBE DE EDUCACIÓN EN SALUD PÚBLICA. I Conferencia Panamericana de Educación en Salud Pública. XVI Conferencia de ALAESP Informe Final. Rio de Janeiro, agosto de 1994, 67p.

9. AYRES, J.R. de C.M. Epidemiologia e emancipação. São Paulo, HUCITEC, 1995.

10. AYRES, J.R. de C.M. Sobre o risco: para compreender a epidemiologia. São Paulo, HUCITEC, 1996.

11. BANCO MUNDIAL. Relatório sobre o desenvolvimento mundial 1993. Investindo em saúde. Indicadores de desenvolvimento mundial. Rio de Janeiro Banco Mundial, 1993.

12. BARRETO, M.L. A epidemiologia, sua história e crises: notas para pensar o futuro. In: Costa, D.C., org. Epidemiologia, teoria e objeto. São Paulo, HUCITEC/ ABRASCO, 1990. p. 19-38.

13. BIBEAU, G. \& CORIN, E. From submission to the text to the violence of interpretation. In: Bibeau, G. \& Corin, E. ed. Beyond textuality: asceticism and violence in anthropological interpretation. Berlin, Mouton de Gruyter, 1995.p.3-54.

14. BOURDIEU, P. O campo científico. In: Ortiz, R. org. Pierre Bourdieu.São Paulo, Ática, 1983.Cap.4.p.122-55. (Coletânea Grandes Cientistas Sociais, 39).

15. BREILH, J. Reprodução social e investigação em saúde coletiva. construção do pensamento e debate. In: Costa, D.C., org. Epidemiologia, teoria e objeto. São Paulo, HUCITEC/ABRASCO, 1990. p.137-65.
16. CANADA. A new perspective on the health of Canadians: a work document. Ottawa, Ministry of Health and Welfare, April 1974, 76p + anexos.

17. CANADA. Ottawa Charter for Health Promotion: an international conference on health promotion. Ottawa, WHO/Ministry of Health and Welfare, 1986.

18. CANESQUI, A.M. org. Ciências sociais e saúde. Rio de Janeiro, HUCITEC/ABRASCO, 1997.

19. CASTELLANOS, P.L. Sistemas nacionales de vigilância de la situatión de salud según condiciones de vida y del impacto de las acciones de salud y bienstar. Washington, D.C., OPS/ OMS, 1991

20. CASTIEL, L.D. O buraco e o avestruz: a singularidade do adoecer humano. Campinas, Papirus, 1994.

21. CZERESNIA, D. Do contágio à transmissão: ciência e cultura na gênese do conhecimento epidemiológico. Rio de Janeiro, Editora Fiocruz, 1997.

22. DESROSIERS, G. Évolution des conceptes et pratiques modernes en santé publique. Ruptures, 3(1):18-28, 1996.

23. DEVER, G.E.A. A epidemiologia na administração dos serviços de saúde. São Paulo, Pioneira, 1988. p.1-24.

24. DONNANGELO, M.C.F. Saúde e sociedade. São Paulo, Duas Cidades, 1976.

25. DONNANGELO, M.C.F. A pesquisa na área da saúde coletiva no Brasil: a década de 70. In: ABRASCO. Ensino da saúde pública, medicina preventiva e social no Brasil. Rio de Janeiro, ABRASCO/NUTES/CLATES, 1982. p.1735

26. ESCUELA DE SALUD PUBLICA. Organizacion Paname-ricana de Salud. Salud Publica. Ciencia, Politica y Accion (Memorias de la I Reunion Andina sobre Desarrollo de la Teoria y la Practica en Salud Publica) Quito, 1993, 160p.

27. FEE, E. Disease and discovery: a history of the John Hopkins School of Hygiene and Public Health - 1916-1939. Baltimore, The John Hopkins University Press, 1987.

28. FERREIRA, J.R. La crisis. In: Organización Panamericana de la Salud. La crisis de la salud pública: reflexiones para el debate. Washington, D.C., 1992. p. 233-36. (OPS Publicación Científica, 540).

29. FLEURY, S. As ciências sociais em saúde no Brasil. In: Nunes, E.D. org. As ciências sociais em saúde na América Latina: tendências e perspectivas. Brasília, Organização Panamericana da Saúde, 1985. p.87-109.

30. FLEURY, S. O dilema da reforma sanitária brasileira. In: Berlinguer, G.; Fleury, S.; Campos, G.W.de S. Reforma sanitária - Itália e Brasil. São Paulo, HUCITEC/CEBES, 1988. p.195-207. 
31. FOUCAULT, M. Naissance de la clinique: une archeologie du régard médical. Paris, PUF, 1966.

32. FOUCAULT, M. Surveiller et punir. Paris, Gallimard, 1979.

33. FRENK, J. La nueva salud pública. In: Organización Panamericana de la Salud. La crisis de la salud pública: reflexiones para el debate. Washington, D.C., 1992. p. 75-93 (OPS - Publicación Científica, 540).

34. GARCIA, J.C. Paradigmas para la enseñanza de las ciencias sociales en las escuelas de medicina. Educ. Med. Salud, 5:130-64, 1971 .

35. GAUMER, B. Evolution du concept de la santé publique dans quelques pays industrialisé du bloc occidental de la fin du XVIII e siécle aux années 1970. Ruptures, 2(1):37-55, 1995.

36. GRANDA, E. Salud pública: sujeito y acción. In: Conferencia Panamericana de Educación en Salud Pública. Conferencia de la Associacion Latinoamericana y del Caribe de Educación en Salud Pública, 16., Rio de Janeiro, 1994.

37. GRUNDY, F. \& MACKINTOSH, J.M. L'enseignement de l'hygiéne et de la santé publique en Europe. Genève, Organisation Mondiale de la Santé, 1958.

38. HABERMAS, J. Teoria y praxis: estudios de filosofia social. 2a. ed. Madrid, Tecnos, 1990.

39. INSTITUTE OF MEDICINE. The future of public health. Washington, D.C.; National Academy Press, 1988.

40. IRIART, C.; NERVI, L.; OLIVIER, TESTA, M. Tecnoburocracia sanitaria: ciencia, ideologia y profissionalización en la salud pública. Buenos Aires, Lugar Editorial, 1994

41.KUHN, T. The structure of scientific revolutions. Chicago, University of Chicago Press, 1970.

42.LATHEM, W. Community medicine: success or failure? $N$. Eng. J. Med., 14:18-23, 1976.

43.LAURELL, A C.Tendencias actuales de la epidemiologia social [Conferência apresentada noa 3er Congreso Panamericano de Epidemiologia, Cordoba, Argentina, Octubre 1994].

44.LAURELL, A.C.\& NORIEGA, M. Processo de produção e saúde: trabalho e desgaste operário. São Paulo, HUCITEC, 1989.

45. LEAVELL, H. \& CLARK, E.G. Medicina preventiva. São Paulo, McGraw-Hill, 1976.

46. MACEDO, C.G. El contexto. In: Organización Panamericana de la Salud. La crisis de la salud pública: reflexiones para el debate. Washington, D.C., 1992. p. 23743. (OPS - Publicación Científica, 540).

47. MENDES, E.V. A construção social da vigilância à saúde no Distrito Sanitário. In: Mendes, C.V., org. A vigilância à saúde no distrito sanitário. Brasília, Organização Panamericana da Saúde, 1993 p.7-19. (Série de Desenvolvimento de Serviços de Saúde, 10).
48. MENDES, E.V. org. A vigilância à saúde no distrito sanitário. Brasília. OPS/OMS, 1993, (Série de Desenvolvimento de Serviços de Saúde, 10).

49. MENDES GONÇALVES, R.B. Medicina e história. Raizes sociais do trabalho médico. [Dissertação de mestrado, área de Medicina Preventiva do Curso de Pós-Graduação da Faculdade de Medicina da Universidade de São Paulo, 1979, 209p].

50. MENDES GONÇALVES, R.B. O processo tecnológico do trabalho em saúde. Divulg. saúde deb., 4:97-102, 1991.

51. MENDES GONÇALVES, R.B. Seres humanos e práticas de saúde: comentários sobre "razão e planejamento". In: Gallo, E. org. Razão e planejamento: reflexões sobre política, estratégia e liberdade. São Paulo, HUCITEC/ABRASCO. 1995. p.13-31.

52. MYNAIO, M.C. de S. Um desafio sociológico para a educação médica. Rev. Bras. Educ. Méd., 15:25-32, 1991.

53. MINAYO, M.C. O desafio do conhecimento. São Paulo, HUCITEC-ABRASCO, 1992.

54. NCAYIYANA, D.; GOLDSTEIN, G.; GOON, Y. D. New public health and WHO's Ninth Programme of Work: a discussion paper. Geneva, WHO Division of Development of Human Resources, 1995.

55. ORGANIZACION PANAMERICANA DE LA SALUD. Desarrollo de la teoria y práctica de la salud publica en la Region de las Americas (1990-1995). Washington, DC. s/d.

56. ORGANIZACIÓN PANAMERICANADE LA SALUD Recursos humanos y sistemas locales de salud. Washington, D.C., 1994. (Serie Desarrollo de Recursos Humanos, 99, Desarrollo y fortalecimiento de Sistemas Locales de Salud HSS/SILOS , 31)

57. ORGANIZAÇÃO PANAMERICANA DE SAÚDE. Orientações estratégicas e programáticas: 1995-1998. Washington, D.C., 1995 . (Documento Oficial, 269).

58. PAIM, J.S. Medicina comunitária: introdução a uma análise crítica. Saúde debate, (1):9-12, 1976.

59. PAIM, J.S. Desenvolvimento teórico-conceitual do ensino em saúde coletiva. In: ABRASCO. Ensino da saúde pública, medicina preventiva e social no Brasil. Rio de Janeiro, ABRASCO/NUTES/CLATES,1982. p.3.

60. PAIM, J.S. Saúde, crises, reformas. Salvador, Centro Editorial e Didático da UFBa, 1986.

61. PAIM, J.S. Collective health and the challenges of practice In: Pan American Health Organization The crisis of public health: reflections for the debate. Washington, 1992. p. 13650. (Scientific Publication, 540).

62. PAIM, J. S. A reforma sanitária e os modelos assistenciais. In: Rouquayrol, M.Z. Epidemiologia \& saúde. 4a ed. Rio de Janeiro, MEDSI, 1993a. p. 455-66.

63. PAIM, J.S. Marco de referência para um programa de educação continuada em saúde coletiva. Rev. Bras. Educ. Méd.,17:7-13, 1993b. 
64. PAIM, J.S Recursos humanos em saúde no Brasil: problemas crônicos e desafios agudos. São Paulo, Faculdade de Saúde Pública/USP, 1994.

65. PAN AMERICAN HEALTH ORGANIZATION. The crisis of public health: reflections for the debate. Washington, D.C., 1992. (Scientific Publication, 540).

66. POSSAS, C. Epidemiologia e sociedade. São Paulo, HUCITEC, 1989. p.179-234.

67. RIBEIRO, P.T. A instituição do campo científico da saúde coletiva no Brasil. Rio de Janeiro, 1991. [Dissertação de Mestrado - Escola Nacional de Saúde Pública].

68. RODRIGUES NETO, E. Integração docente-assistencial em saúde. São Paulo, 1979. [Dissertação de Mestrado Faculdade de Medicina da USP].

69. RODRIGUEZ, R. Teoria y practica de la salud pública.Washington, D.C., Organización Panamericana De La Salud, 1994. [Documento não publicado de circulação restrita].

70. ROSEN, G. Da polícia médica à medicina social. Rio de Janeiro, Graal, 1980. p. 77-141, 213-42.

71. SAMAJA, J. Epistemologia e metodología. Buenos Aires, EUDEBA, 1994.

72. SAMAJA, J. La reproducción social y la relación entre la salud y las condiciones de vida: elementos teóricos e metodológicos para re-examinar la questión de las relaciones entre salud y condiciones de vida. s.n.t.

73. SCHRAIBER, L.B. Políticas públicas e planejamento nas práticas de saúde. Saúde deb., (47):28-35, 1995.

74. SCHRAIBER, L.B. \& MENDES-GONÇALVES, R.B. Necessidades de saúde e atenção primária. In: Schraiber, L.B.; Nemes, M.I.; Mendes-Gonçalves, R.B. org. Saúde do adulto: programas e ações na unidade básica. São Paulo, HUCITEC, 1996. p.29-47.

75. SCHRAIBER, L.B.; NEMES, M.I.B.; MENDES GONÇALVES, R.B. org. Saúde do adulto: programas $e$ ações na unidade básica. São Paulo, HUCITEC, 1996.
76. SCHRAIBER, L.B. org. Programação em saúde, hoje. São Paulo, HUCITEC, 1990.

77. SERVA, M. O paradigma da complexidade e a análise organizacional. Rev. Adm. Emp., 32(2):26-35, 1992.

78. SILVA, G.R. Origens da medicina preventiva como disciplina do ensino médico. Rev. Hosp. Clin. Fac. Med. S. Paulo, 28(2):31-5, 1973

79. SOUZA, M. de F.M. \& KALICHMAN, A. O. Vigilância à saúde: epidemiologia, serviços e qualidade de vida. In: Rouquayrol, M.Z. org. Epidemiologia \& Saúde. Rio de Janeiro, MEDSI 1993. p.467-76.

80. TEIXEIRA, C.F.\& MELO, C. org. Construindo distritos sanitários: a experiência da cooperação italiana no Município de São Paulo. São Paulo,HUCITEC/Cooperação Italiana em Saúde, 1995.

81. TERRIS, M. Tendencias actuales en la salud publica de las Americas. In: Organización Panamericana de la Salud. La crisis de la salud pública: reflexiones para el debate. Washington, D.C., 1992. p. 185-204. (OPS - Publicación Científica, 540)

82. TESTA, M. Pensar em saúde. Porto Alegre, Artes Médicas/ ABRASCO, 1992a.

83. TESTA, M. Salud publica: acerca de su sentido y significado. In: Organización Panamericana de la Salud. La crisis de la salud pública: reflexiones para el debate. Washington, D.C., 1992b. p. 205-29. (OPS - Publicación Científica, 540).

84. TESTA, M. Pensamento estratégico e lógica de programação: o caso da saúde. São Paulo, HUCITEC/ ABRASCO, 1995.

85. WORLD HEALTH ORGANIZATION. Renewing the healthfor-all strategy: elaboration of a policy for equity, solidarity and health. Geneva, 1995.

86. WORLD HEALTH ORGANIZATION. New public health and WHO's Ninth General Programme of Work: a discussion paper. Geneva, WHO, 1995.

87. WORLD BANK. Priorities in health research \& development. [Report of Ad-hoc committee, 6th. draft], Cape Town, 1996. 